\title{
ZASTOSOWANIE FUNKCJONAŁU HU-WASHIZU W PLASTYCZNEJ ANALIZIE MES PŁYT GRUBYCH
}

\begin{abstract}
W pracy sformułowano oryginalny, autorski funkcjonał dla zagadnień teorii plastyczności. Podstawą był funkcjonał Hu-Washizu z teorii sprężystości. Przyrostowa postać funkcjonału pozwala w prosty sposób budować algorytmy MES. Zastosowanie funkcjonału przedstawiono na przykładzie płyty grubej. Zastosowano model warstwowy aby uwzględnić częściowe uplastycznienie przekroju płyty. Algorytm MES dla płyty grubej zbudowano w oparciu o trójkątny trzy węzłowy element skończony z liniowymi funkcjami kształtu dla wszystkich przemieszczeń uogólnionych. Naprężenia i odkształcenia w tego typu elemencie przyjmuje się jako stałe. Przedstawiony algorytm nie wymaga żadnych dodatkowych równań teorii plastyczności i jest równoważny stowarzyszonemu prawu płynięcia plastycznego. Algorytm prowadzi do nieliniowego, przyrostowego układu równań algebraicznych, który rozwiązuje się metodą Newtona. Kilka prostych przykładów pozytywnie weryfikuje przyjęte założenia i stosowane algorytmy.
\end{abstract}

Słowa kluczowe: płyta Reissnera-Mindlina, model warstwowy płyty, warunek plastyczności Hubera-Misesa-Hencky’ego

\section{Wprowadzenie}

Celem pracy jest zastosowanie zmodyfikowanego funkcjonału $\mathrm{Hu}-$ Washizu[1], omówionego przez autorów w pracy [2]. Jego argumentami (1) są: $\sigma_{i j}, \varepsilon_{i j}, u_{i}, \lambda$, odpowiednio funkcje naprężeń, odkształceń, przemieszczeń i parametr określający przyrost odkształceń plastycznych; górny indeks " oznacza wielkości w poprzednim kroku, a nadkreślenie ${ }^{-}$odkształcenie plastyczne. Minimalizacja tego funkcjonału prowadzi do równań teorii plastyczności dla stowarzyszonego prawa plastycznego płynięcia. Możliwe jest sformułowanie funkcjonału dla dowolnego warunku plastyczności $\Phi$ (także ze wzmocnieniem).

\footnotetext{
${ }^{1}$ Autor do korespondencji/corresponding author: Jakub Lewandowski, Politechnika Wrocławska, Wybrzeże Wyspiańskiego 27, 50-370 Wrocław, tel.: 71320 4852, jakub.lewandowski@pwr.edu.pl

${ }^{2}$ Kazimierz Myślecki, Politechnika Wrocławska, Wybrzeże Wyspiańskiego 27, 50-370 Wrocław, tel.: 71320 2477, kazimierz.myslecki@pwr.edu.pl
} 


$$
\begin{aligned}
& \Pi\left(\sigma_{i j}, \varepsilon_{i j}, u_{i}, \lambda\right)=\frac{1}{2} \int_{V} C_{i j k l}\left(\varepsilon_{i j}-\varepsilon_{i j}^{n}\right)\left(\varepsilon_{k l}-\varepsilon_{k l}^{n}\right) d V- \\
& -\int_{V}\left(\sigma_{i j}-\sigma_{i j}^{n}\right)\left[\varepsilon_{i j}+\bar{\varepsilon}_{i j}^{n}-\frac{1}{2}\left(u_{i},{ }_{j}+u_{j},_{i}\right)\right] d V- \\
& -\int_{V} \Delta F_{i} u_{i} d V-\int_{V} \lambda \Phi\left(\sigma_{i j}\right) d V
\end{aligned}
$$

W artykule [2] zajmowano się zadaniami płaskiego stanu naprężenia. Niniejsza publikacja ma na celu wyprowadzenie równań MES dla płyty grubej (Reissnera-Mindlina).Zastosowano model warstwowy płyty, tzn. taki, w którym uplastycznieniu mogą ulegaćposzczególne warstwy, a nie cały przekrój.

\section{Płyta gruba}

\subsection{Podstawowe równania}

Przemieszczenia uogólnione odniesione do powierzchni środkowej płyty schematycznie pokazano na Rys. 1.

Równania [3] wiążące uogólnione siły, odkształcenia i przemieszczenia odniesione do powierzchni środkowej płyty z odpowiadającymi im wielkościami $\mathrm{w}$ dowolnym punkcie materialnym przedstawiono w zapisie macierzowym:

$\boldsymbol{\sigma}=\left\{M_{11}, M_{22}, M_{12}, Q_{1}, Q_{2}\right\}-$ siły wewnętrzne

$\boldsymbol{\varepsilon}=\left\{\kappa_{11}, \kappa_{22}, 2 \kappa_{12}, \gamma_{1}, \gamma_{2}\right\}-$ uogólnione odkształcenia

$\mathbf{u}=\left\{\delta_{1}, \delta_{2}, w\right\}-$ uogólnione przemieszczenia

$\mathbf{f}=\left\{m_{1}, m_{2}, q\right\}-$ intensywność momentów i obciążeń pionowych

$$
z=x_{3}, \quad M_{\alpha \beta}=\int_{-H / 2}^{H / 2} z \sigma_{\alpha \beta} d z, \quad Q_{\alpha}=\int_{-H / 2}^{H / 2} \sigma_{\alpha z} d z
$$

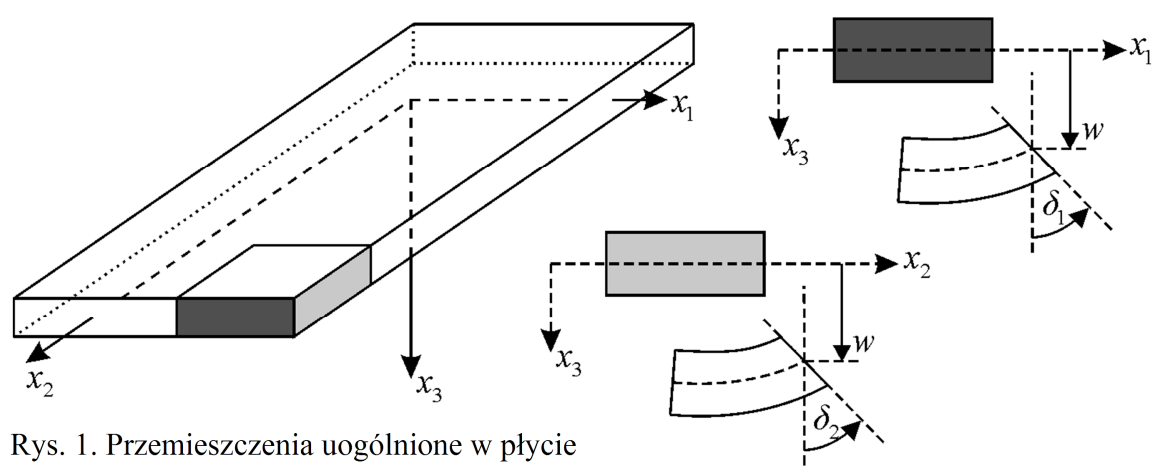

Fig. 1. Generalized displacements ofplate 


$$
\left\{\begin{array}{l}
\kappa_{11}=\delta_{1,1} \\
\kappa_{22}=\delta_{2,2} \\
2 \kappa_{12}=\delta_{1,2}+\delta_{2,1} \\
\gamma_{1}=\delta_{1}+w_{, 1} \\
\gamma_{2}=\delta_{2}+w_{, 2}
\end{array} \Rightarrow \boldsymbol{\varepsilon}=\left[\begin{array}{ccc}
\frac{\partial}{\partial x_{1}} & 0 & 0 \\
0 & \frac{\partial}{\partial x_{2}} & 0 \\
\frac{\partial}{\partial x_{2}} & \frac{\partial}{\partial x_{1}} & 0 \\
1 & 0 & \frac{\partial}{\partial x_{1}} \\
0 & 1 & \frac{\partial}{\partial x_{2}}
\end{array}\right] \mathbf{u} \Leftrightarrow \boldsymbol{\varepsilon}=\mathbf{L u}\right.
$$

Przy oznaczeniach (2) i (3) funkcjonał (1) dla płyty grubej, w zapisie macierzowym przyjmie postać

$$
\begin{aligned}
& \Pi(\boldsymbol{\sigma}, \boldsymbol{\varepsilon}, \mathbf{u}, \lambda)=\frac{1}{2} \int_{A}\left(\boldsymbol{\varepsilon}-\boldsymbol{\varepsilon}^{n}\right)^{T} \mathbf{C}\left(\boldsymbol{\varepsilon}-\boldsymbol{\varepsilon}^{n}\right) d A-\int_{A}\left(\boldsymbol{\sigma}-\boldsymbol{\sigma}^{n}\right)^{T}\left(\boldsymbol{\varepsilon}+\overline{\boldsymbol{\varepsilon}}^{n}-\mathbf{L u}\right) d A- \\
& -\int_{A}\left(\Delta \mathbf{f}^{T} \mathbf{u}\right) d A-\int_{A} \lambda \Phi(\boldsymbol{\sigma}) d A
\end{aligned}
$$

gdzie

$$
\mathbf{C}=\left[\begin{array}{ccccc}
D & v D & 0 & 0 & 0 \\
v D & D & 0 & 0 & 0 \\
0 & 0 & \frac{1}{12} G H^{3} & 0 & 0 \\
0 & 0 & 0 & \frac{5}{6} G H & 0 \\
0 & 0 & 0 & 0 & \frac{5}{6} G H
\end{array}\right], \quad D=\frac{E H^{3}}{12\left(1-v^{2}\right)}, \quad G=\frac{E}{2(1+v)}
$$

a $E, v$ i $H$ są odpowiednio: modułem Younga, współczynnikiem Poissona i grubością płyty.

\subsection{Model warstwowy płyty}

Forma funkcjonału (4) nie pozwala na analizę zagadnienia, kiedy uplastycznieniu ulega nie cały przekrój, a jedynieposzczególne warstwy płyty. W funkcjonale, należy zatem, siły wewnętrzne i uogólnioneodkształcenia zastąpićnaprężeniami normalnymi i stycznymioraz odkształcenia normalnymi i postaciowymi.Z założonego $\mathrm{w}$ teorii płyt parabolicznego rozkładu naprężeń $\tau_{13}$, $\tau_{23}$ orazliniowego rozkładu naprężeń $\sigma_{1}, \sigma_{l}, \tau_{12}$ można wyprowadzić następujące związki 


$$
\left\{\begin{array}{l}
Q_{\alpha}=\int_{H} \tau_{\alpha 3}(z) f(z) d z \\
M_{\alpha \alpha}=\int_{H} \sigma_{\alpha}(z) g(z) d z, \quad f(z)=\frac{5}{4}\left(1-4 \frac{z^{2}}{H^{2}}\right), g(z)=z \\
M_{12}=\int_{H} \tau_{12}(z) g(z) d z
\end{array}\right.
$$

Stąd dzieląc przekrój płyty na warstwy (Rys. 2)otrzymamy zależności

$$
\left\{\begin{array}{l}
\int_{H} \tau_{\alpha 3}(z) f(z) d z \approx \sum_{i=1}^{N} \tau_{\alpha 3 ; i} f_{i} h_{i} \\
\int_{H} \sigma_{\alpha}(z) g(z) d z \approx \sum_{i=1}^{N} \sigma_{\alpha ; i} g_{i} h_{i}, f_{i}=f\left(z_{i}\right)=\frac{5}{4}\left(1-\frac{4 z_{i}^{2}}{H^{2}}\right), g_{i}=g\left(z_{i}\right)=z_{i} \\
\int_{H} \tau_{12}(z) g(z) d z \approx \sum_{i=1}^{N} \tau_{12 ; i} g_{i} h_{i}
\end{array}\right.
$$

Przybliżone związki (7) stają się dokładnymi po przejściu granicznym $N \rightarrow \infty$.

Po uwzględnieniu podziału na warstwy funkcjonał przyjmie następującą postać

$$
\begin{aligned}
& \Pi\left(\mathbf{S}_{i}, \mathbf{E}_{i}, \mathbf{u}, \boldsymbol{\Lambda}_{i}\right)=\frac{1}{2} \int_{A} \sum_{i=1}^{N}\left[\left(\mathbf{E}_{i}-\mathbf{E}_{i}^{n}\right)^{T} \mathbf{C}\left(\mathbf{E}_{i}-\mathbf{E}_{i}{ }^{n}\right) h_{i}\right] d A- \\
& -\int_{A} \sum_{i=1}^{N}\left[\left(\mathbf{S}_{i}-\mathbf{S}_{i}{ }^{n}\right)^{T}\left(\mathbf{E}_{i}+\overline{\mathbf{E}}_{i}^{n}-\mathbf{M L u}\right) h_{i}\right] d A- \\
& -\int_{A}\left(\Delta \mathbf{f}^{T} \mathbf{u}\right) d A-\int_{A} \sum_{i=1}^{N}\left[\boldsymbol{\Lambda}_{i} \Phi_{i}\left(\mathbf{S}_{i}\right) h_{i}\right] d A \\
& \left\{\begin{array}{l}
\mathbf{S}_{i}=\left\{\sigma_{1}, \sigma_{2}, \tau_{12}, \tau_{13}, \tau_{23}\right\}_{i}, \\
\mathbf{E}_{i}=\left\{\varepsilon_{1}, \varepsilon_{2}, \gamma_{12}, \gamma_{13}, \gamma_{23}\right\}_{i}
\end{array}, \quad\right. \text { numerwarstwy }
\end{aligned}
$$

gdzie

$$
\mathbf{C}=\left[\begin{array}{ccccc}
\frac{E}{1-v^{2}} & \frac{v E}{1-\nu^{2}} & 0 & 0 & 0 \\
\frac{v E}{1-v^{2}} & \frac{E}{1-v^{2}} & 0 & 0 & 0 \\
0 & 0 & G & 0 & 0 \\
0 & 0 & 0 & G & 0 \\
0 & 0 & 0 & 0 & G
\end{array}\right], \mathbf{M}=\left[\begin{array}{ccccc}
g_{i} & 0 & 0 & 0 & 0 \\
0 & g_{i} & 0 & 0 & 0 \\
0 & 0 & g_{i} & 0 & 0 \\
0 & 0 & 0 & f_{i} & 0 \\
0 & 0 & 0 & 0 & f_{i}
\end{array}\right]
$$




\section{Algorytm MES}

Wprowadza się trójkątny element skończony o liniowych funkcjach kształtu dla przemieszczeń i stałych wartościach naprężeń i odkształceń [4]

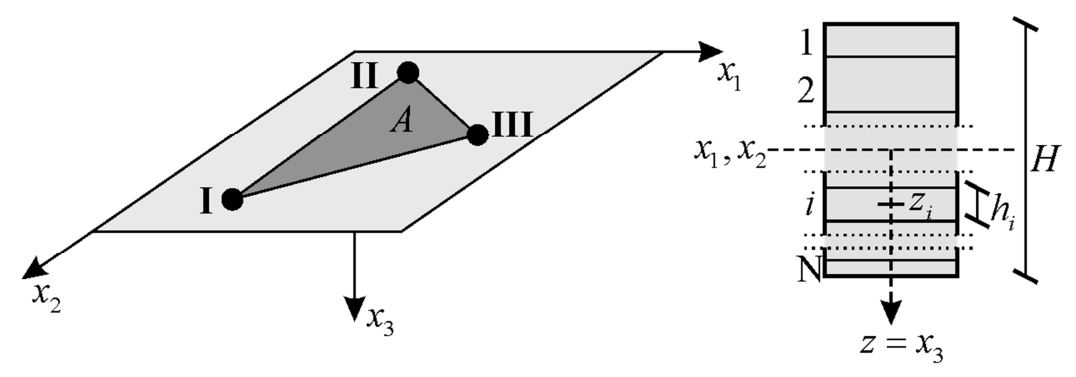

Rys. 2. Warstwowy,trójkątny płytowy element skończony

Fig. 2. Triangular, layered plate finite element

Aproksymację przemieszczeń można opisać współrzędnymi powierzchniowymi $L_{I}, L_{I I}, L_{I I I}$

$$
\begin{aligned}
\mathbf{q} & =\left\{\delta_{1}^{I}, \delta_{2}^{I}, w^{I}, \delta_{1}^{I I}, \delta_{2}^{I I}, w^{I I}, \delta_{1}^{I I I}, \delta_{2}^{I I I}, w^{I I I}\right\} \\
\mathbf{u} & =\left[\begin{array}{ccccccccc}
L_{I} & 0 & 0 & L_{I I} & 0 & 0 & L_{I I I} & 0 & 0 \\
0 & L_{I} & 0 & 0 & L_{I I} & 0 & 0 & L_{I I I} & 0 \\
0 & 0 & L_{I} & 0 & 0 & L_{I I} & 0 & 0 & L_{I I I}
\end{array}\right] \mathbf{q}=\mathbf{N q}
\end{aligned}
$$

Po dyskretyzacji i scałkowaniu funkcjonał przyjmie następującą postać

$$
\begin{aligned}
& \Pi\left(\mathbf{S}_{i}, \mathbf{E}_{i}, \mathbf{q}, \boldsymbol{\Lambda}_{i}\right)=\frac{1}{2} \sum_{i=1}^{N}\left(\mathbf{E}_{i}-\mathbf{E}_{i}^{n}\right)^{T} \mathbf{C}\left(\mathbf{E}_{i}-\mathbf{E}_{i}^{n}\right) V_{i}- \\
& \sum_{i=1}^{N}\left(\mathbf{S}_{i}-\mathbf{S}_{i}^{n}\right)^{T}\left(\mathbf{E}_{i}+\overline{\mathbf{E}}_{i}^{n}-\mathbf{B q}\right) V_{i}-\Delta \mathbf{F}^{T} \mathbf{q}-\sum_{i=1}^{N} \boldsymbol{\Lambda}_{i} \Phi_{i}\left(\mathbf{S}_{i}\right) V_{i}
\end{aligned}
$$

gdzie, po uwzględnieniu warunku plastyczności Hubera-Misesa-Hencky’ego (HMH) w każdej warstwie, otrzymuje się

$$
\begin{aligned}
& \boldsymbol{\psi}=\left[\begin{array}{ccccc}
2 & -1 & 0 & 0 & 0 \\
-1 & 2 & 0 & 0 & 0 \\
0 & 0 & 6 & 0 & 0 \\
0 & 0 & 0 & 6 & 0 \\
0 & 0 & 0 & 0 & 6
\end{array}\right], \mathbf{B}=\int_{A} \mathbf{M L N} d A, \mathbf{F}=\int_{A} \mathbf{N}^{T} \mathbf{f} d A \\
& \Phi_{i}\left(\mathbf{S}_{i}\right)=\left(\frac{1}{2} \mathbf{S}_{i}^{T} \boldsymbol{\psi} \mathbf{S}_{i}-\sigma_{0}{ }^{2}\right), \text { warunek HMH z granicą plastyczności } \sigma_{0} \\
& V_{i}=A h_{i}
\end{aligned}
$$


Minimalizacja funkcjonału prowadzi do równania MES dla pojedynczego elementu skończonego (13). Równanie to przedstawiono jedynie w sposób ideowy, pomijając różnorodne możliwości rozkładu warstw uplastycznionych

$$
\left[\begin{array}{cccc}
0 & 0 & \mathbf{B}^{T} V & 0 \\
0 & \mathbf{C} V & -\mathbf{I} V & 0 \\
\mathbf{B} V & -\mathbf{I} V & 0 & \mathbf{K}_{\mathrm{S}}^{\mathrm{S} \Lambda} \\
0 & 0 & \mathbf{K}_{\mathrm{S}}^{\Lambda S} & 0
\end{array}\right]\left\{\begin{array}{l}
\mathbf{q} \\
\mathbf{E} \\
\mathbf{S} \\
\Lambda
\end{array}\right\}=\left(\begin{array}{c}
\Delta \mathbf{F}+\mathbf{B}^{T} \mathbf{S}^{n} V \\
\mathbf{C E}^{n} V-\mathbf{S}^{n} V \\
\overline{\mathbf{E}^{n}} V \\
-\sigma_{0}^{2} V
\end{array}\right)
$$

Macierze $\mathbf{K}_{\mathrm{S}}{ }^{\Lambda \mathrm{S}}{ }_{\mathrm{i}} \mathbf{K}_{\mathrm{S}}{ }^{\mathrm{S} \Lambda}$ są zależne od $\mathbf{S}$ oraz $\Lambda$. Zatem układ równań jest nieliniowy. Obowiązuje on w zakresie plastycznego płynięcia w procesie obciążania elementu. W przypadku obciążenia/odciążenia, gdy naprężenia znajdują się wewnątrz obszaru ograniczonego powierzchnią plastyczności, obowiązuje układ równań bez szarych elementów. Problem ten oraz algorytm rozwiązania zostałomówiony w [2].

\section{Przykłady numeryczne}

\subsection{Ugięcie płyty w stanie sprężystym}

Przedmiotem analizy numerycznej była płyta kwadratowa oproporcji grubości do wymiaru boku $(a)$ jak 1:10, podparta przegubowo na wszystkich krawędziach, obciążona równomiernie obciążeniem q. Siatka MES składała się z $128(8 \times 8 \times 2)$ trójkątnych ES i 6 warstw.Sprawdzono poprawność rozwiązania sprężystego ugięcia płyty poprzez porównanie z wynikiem analitycznym

$$
w_{0}=0,004062 \frac{q a^{4}}{D}
$$

Różnica wyników numerycznego i analitycznego wynosiła 3\%, co świadczy o dobrym przybliżeniu poprzez model warstwowy, nawet przy rzadkiej siatce elementów skończonych i niewielkiej liczbie warstw.

\subsection{Zginanie walcowe płyty wspornikowej w stanie plastycznym}

Drugi przykład to płyta kwadratowa $(1 \mathrm{~m} \times 1 \mathrm{~m} \times 0.1 \mathrm{~m})$ zamocowana sztywno na jednej krawędzi i obciążona momentem rozłożonym o stałej intensywności na krawędzi przeciwległej. Wartość momentu została tak dobrana, aby wewnętrzna część przekroju (połowa) znajdowała się w stanie sprężystym, a zewnętrzna w plastycznym (Rys. 3). Przyjęto siatkę 128 elementów i 4 warstwy. Ze względu na małą liczbę warstw, uplastycznienie dwu zewnętrznych warstw w całej płycie wystąpiło przy większej wartości momentu (110\%) niż obliczona analitycznie dla równoważnej belki. Jest to niewielka różnica biorąc pod uwagę małą liczbę warstw przyjętą do analizy MES. 


\subsection{Płyta kwadratowa, podparta swobodnie z obciążeniem równomiernie rozłożonym $w$ stanie plastycznym}

Ostatnim przykładem jest płyta kwadratowao proporcji grubości do wymiaru boku jak 1:10, obciążona równomiernie podzielona na $72(6 \times 6 \times 2)$ elementy i 4 warstwy (Rys. 3)
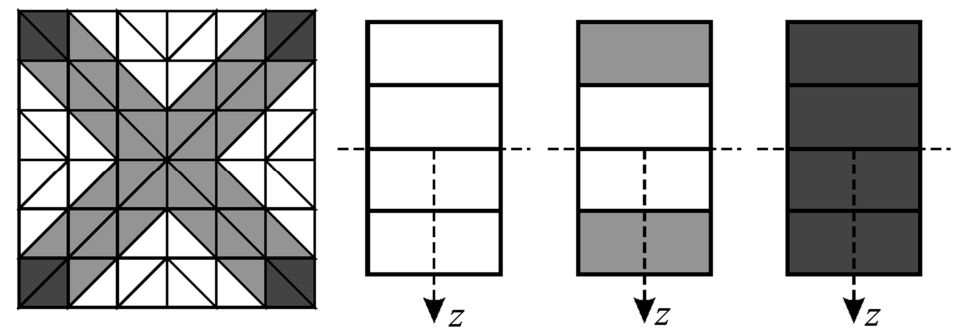

Rys. 3. Siatka ES wraz ze strefami plastycznymi oraz uplastycznione warstwy

Fig. 3. FE mesh with plastic regions and layers

Tylko białe ES nie uległy uplastycznieniu. Stan pozostałych odpowiada rysunkom przekrojów (Rys. 3).Analizę numeryczną o identycznych parametrach, geometrii i siatce elementów skończonych przeprowadzono w programie Abaqus. Uzyskano taki sam rozkład stref plastycznych,choć różnice w ugięciach w środku płyty wynoszą $40 \%$.

\section{Uwagi końcowe}

Przedstawiony $\mathrm{w}$ artykule funkcjonał jest funkcjonałem zupełnym zagadnienia teorii plastycznościi nie wymaga żadnych dodatkowych warunków nakładanych na parametry funkcjonału. Zastosowany warstwowy model płyty grubej pozwala na analizę MES częściowo uplastycznionych w przekroju płyt. Zaprezentowane przykłady numeryczne wskazują na dobrą zgodność wyników z innymi rozwiązaniami. Obserwowane różnice wynikają z ograniczeń zastosowanego środowiska programistycznego - Mathematici, w którym nie udało się zwiększyć gęstości siatki elementów skończonych i liczby warstw płyty.

Zaprezentowany algorytm warstwowy łatwo można zaadaptować do analizy rzeczywistych płyt warstwowych, z warstwami o różnych własnościach sprężystych i plastycznych.

\section{Literatura}

[1] Washizu K., Variational Methods in Elasticity and Plasticity $3^{\text {rd }}$ ed. , Pergamon Press, New York 1982.

[2] Myślecki K., Lewandowski J., Modified Hu-Washizu principle as a general basis for FEM plasticity equations, $3^{\text {rd }}$ Polish Congress of Mechanics and $21^{\text {st }}$ International 
Conference on Computer Methods in Mechanics Short Papers Vol. 1, PTMTS, Gdańsk 2015.

[3] Reddy J. N., Theory and Analysis of Elastic Plates and Shells $2^{\text {nd }}$ Edition, CRC Press, New York 2006.

[4] Zienkiewicz O.C., Taylor R.L., The Finite Element Method Vol. 1: The Basis $5^{\text {th }}$ ed., Butterworth-Heinemann, Oxford 2000.

\section{HU-WASHIZU FUNCTIONAL APPLICATION IN FEM PLASTIC ANALYSIS OF THICK PLATES}

\section{S u m m a r y}

In this paper original functional for plasticity problems is formulated. It is based on $\mathrm{Hu}-$ Washizu functional for elasticity. Its incremental form allows to build FEM algorithms in a simple way. The functional application is presented on thick plate example. Multi-layered model is assumed to enable partial plastification of the plate section. An algorithm for thick plate is shown for triangular finite element with linear shape functions for all general displacements. Stresses and strains in such an element are constant. The presented algorithm does not require any additional plasticity theory equations and it corresponds to the associated flow rule. It leads to set of nonlinear incremental algebraic equations which are solved by Newton method. Verification of the functional and the algorithm is done on several simple examples.

Keywords: Reissner-Mindlin plate, multi-layered plate, Huber-Mises-Hencky yield condition

Przestano do redakcji: 07.06.2016 r.

Przyjęto do druku: 30.06.2016 r.

DOI: $10.7862 / \mathrm{rb} .2016 .50$ 